\title{
Snake Electrical Energy Production
}

\author{
Prof. Sagar P. Thombare ${ }^{1}$, Prof. Priyanka Hire ${ }^{2}$ \\ HOD, Electrical Department, Matoshri Polytechnic, Nashik, India ${ }^{1}$ \\ Lecturer, Electrical Department, Matoshri Polytechnic, Nashik, India ${ }^{2}$
}

\begin{abstract}
Conceptual Harnessing the energy of waves is an alluring recommendation since they are a great deal more vitality thick than wind. In any case, wave control remains the poor connection of the sustainable power source segment because of the challenges of inexpensively working apparatus in the cruel marine condition. The world's first business wave cultivates just started working a year ago, off the northern shoreline of Portugal. An assortment of different outlines is in trying the world over, yet none are as irregular as the Anaconda. The elastic snake is loaded with freshwater - to help hinder ocean animals from setting up a home inside and fixed at both closures to make a semiunbending inflatable that buoys at the ocean's surface.[1]
\end{abstract}

Keywords: wave energy, snake energy, PCM, power.

\section{INTRODUCTION}

The tube is tied down toward one side and as waves wash along its length they apply weight on the snake that is transmitted by the water inside. This powers Anaconda's dividers to extend outwards into the wave troughs where they are under less weight, shaping "lump waves" that go along the Anaconda's length.

The snake is produced using an elastic based material like that used to make dracones adaptable compartments that are loaded with diesel or water and towed behind boats for brisk and shabby transportation. Other than the turbine, Anaconda has no moving parts and dissimilar to other wave control gadgets it needs just a single tie to the sea floor. That brings down development costs and diminishes the requirement for support - a costly undertaking in seaward settings where erosion and availability are issues, clarifies Rainey.

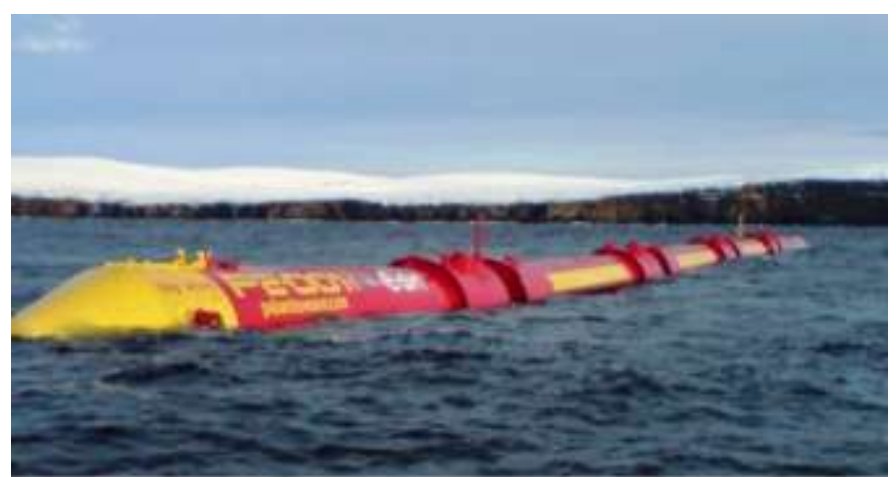

Fig.1: Actual view of Snake Wave energy installation

Work was done in all zones including wave, tidal, stream, and sea flow advances, this paper concentrates on wave vitality assets and related extraction advances as it were.

The report depends on a one of a kind blend of asset evaluation, innovation cost, gadget execution, and market obstruction suppositions to give future cost and organization gauges for wave vitality.

This review addresses the accompanying:

(1) The hypothetical, specialized and commonsense potential for power era from wave vitality

(2) The present lifecycle cost profile (Capex, Opex, and Cost of Electricity) of wave vitality change innovation.

(3) Cost of power varieties as an element of organization site, considering specialized, geo-spatial and electric framework imperatives

(4) Technology cost lessening pathways

(5) Cost decrease

Asset appraisals distinguish geographic area and relative quality of a given asset, however there is critical vulnerability around suppositions that connect asset quality with the measure of electrical power era. 


\section{THE TECHNOLOGY}

The Pelamis Wave Energy Converter is a semi-submerged, enunciated structure comprising of four round and hollow steel segments connected by three pivoted joints. The four segments move with respect to each other and the pivots change over this movement by methods for a controlled pressure driven power transformation framework. Each pivot of the gadget contains its own particular water powered power take off made out of four water powered rams (in each power remove) that oppose this development, pumping high-weight liquid by means of smoothing gatherers to pressure driven engines, which drive enlistment generators to deliver power. A few gadgets can be associated together and connected to shore through a solitary sub-ocean link. The machine is held in position by a mooring arrangement of buoys and weights that keep the mooring links from getting to be noticeably tight. This keeps up enough imperviousness to keep the Pelamis situated however enables the machine to swing head on to approaching waves. The primary full-scale pre-creation Pelamis model was tried at the European Marine Energy Center in Orkney. The plan was autonomously confirmed by WS Atkins as indicated by (DNV) seaward codes and guidelines.

\section{III.PRINCIPLE OF OPERATION}

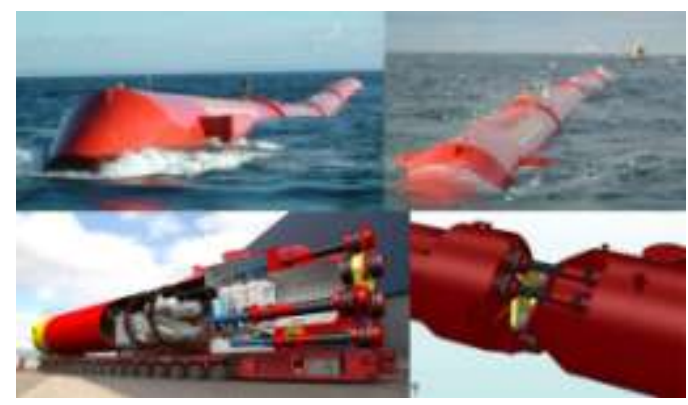

Fig.2: SNAKE Energy Production

The Pelamis P2 is a gliding attenuator. The gadget comprises of five tubular segments, associated by four pivoted control change modules (PCM). Each PCM contains a hurl and influence joint, giving two degrees of opportunity, as outlined in Figure 6. The wave-prompted movement of each area joint is opposed by sets of water powered rams designed as pumps. These pump oil into smoothing gatherers that then release at a consistent rate through a water driven engine coupled to an electrical generator. Every water driven segment are contained inside the gadget barrels.

The gatherers are estimated to permit persistent, smooth yield crosswise over wave gatherings. Oil-to-water warm exchangers are incorporated to dump overabundance control in extensive oceans and give the fundamental warm load in case of loss of the framework. General power transformation effectiveness (mechanical to electrical) ranges from around $70 \%$ at low power levels to more than $80 \%$ at full limit. Each of the four generator sets are connected by a typical $690-\mathrm{V}, 3$-stage transport running the length of the gadget. A solitary transformer is utilized to venture up the voltage to a suitable level for transmission to shore. High voltage power is sustained to the seabed by a solitary adaptable umbilical link, then to shore by means of a regular subsea link. The outline has characteristic survivability with a little frontal zone subjected to the hydrodynamic strengths of substantial waves.

\section{- OFFSHORE TECHNOLOGY}

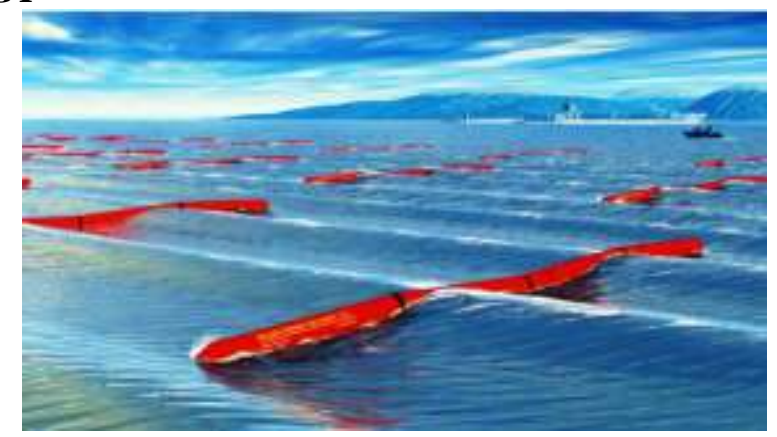

Fig.3: OFFSHORE View

The seaward/marine part's commitment: "No significant specialized obstructions to the improvement of wave vitality models have been recognized. All issues raised under outline, development, arrangement and operation can be tended to by exchange of innovation from different ventures, particularly the seaward business" 


\section{IV.SPECIFICATIONS}

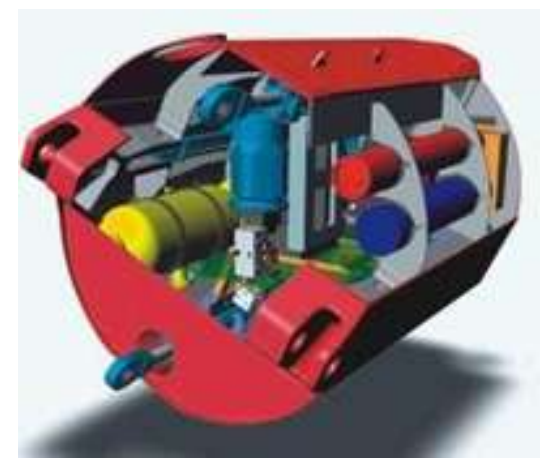

Fig.4: Specification

\section{A. KEY FEATURES}

a) Survivability - center subject...

b) $100 \%$ accessible innovation

c) Hydraulic Power Take Off

d) Power smoothing

e) Tunable

f) Maximum adaptability

g) Minimum deal with site

\section{B. ECONOMIES OF SCALE}

a) Planning

b) Onshore costs, Env. Impacts, Seabed review, Resource appraisal and estimation

c) Cable costs, Cable lay costs, Grid association, Machine establishment Machine

d) Bulk requesting of segments, tooling costs, Plant overhead, Verification costs

\section{i. ADVANTAGES}

$1 \quad 100 \%$ accessible innovation

2 No support completed at seaward site

3 Each machine can give adequate energy to take care of yearly power demand of approx.

\section{ii. DISADVANTAGES}

1 Disturbance or devastation of marine life (counting changes in the conveyance and sorts of marine life close to the shore.

2 Once gadget is harmed we should supplant with new gadget.

\section{CONCLUSION}

Wave vitality is not costly to work and keep up, no fuel is required and no waste is created. In any case, it relies on upon the power of the waves and needs a reasonable site where waves are reliably solid. The framework must have the capacity to withstand harsh climate. Wave control lies not in colossal plants but rather in a blend of on-shore era and close shore era (utilizing an alternate innovation) concentrated on meeting neighbourhood or local needs. On the off chance that this framework turns out to be monetarily conceivable, just $0.1 \%$ of the sustainable power source inside the world's seas could supply more than five times the worldwide interest for vitality. The Pelamis Wave Energy Converter is a progressive idea coming about because of numerous times of designing advancement. It was the world's first business scale machine to produce electrical vitality into the matrix from seaward wave vitality and the first to be utilized as a part of business wave stop ventures.

\section{REFERENCES}

[1] Bent SØrenfen (2004): "Renewable Energy", Elsivier Academic Press, 2004 Edition.

[2] M. Weedy and B. J. Cory (1998): "Electric Power Systems" Wiley, Fourth Edition,

[3] London 1998.

[4] J.N.A. Sarmento, L.M.C. Gato, A.F. de O. Falcão, (1990), "Turbine-controlled wave energy absorption by oscillating-water-column devices". Ocean Engineering, vol. 17, p. 481-497. 
[5] Falcão, P.A.P. Justino, (1995), "OWC wave energy converters with valve-constrained air flow”, Proceedings of the Second European Wave Power Conference European Commission, EUR 16932 EN, p. 187-194

[6] Falcão, P.A.P. Justino, (1999), "OWC Wave Energy Devices with Airflow Control”. Ocean Engineering, vol. 26, p.1249-73.

[7] Brito-Melo, A. (2000), "Modelação e Prédimensionamento de Centrais de Coluna de ÁguaOscilante: Aplicação à Central de Energia das Ondas do Pico, Açores", PhD thesis, IST.

\section{BIOGRAPHIES}

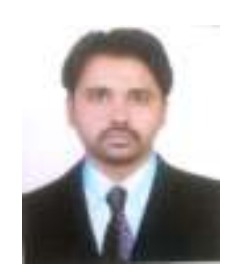

Prof. Sagar P. Thombare, ME (Power Electronic and Drives), Associate Member of Institute of Engineer's,Published Five International Papers in Reputed Journals, Head of Department, Electrical Engineering, Matoshri Aasarabai Polytechnic, Nashik.

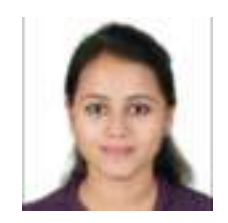

Prof. Priyanka K. Hire, ME (Power System- Appear), Associate Member of Institute of Engineer's, Published One International Papers in Reputed Journals, Lecturer, Electrical Department, Matoshri Aasarabai Polytechnic, Nashik. 